Proc. Indian Acad. Sci. (Chem. Sci.), Vol. 115, No. 4, August 2003, pp 225-239

(C) Indian Academy of Sciences

\title{
Contributions in organic functional group transformations and photochemical and photophysical studies of selective organic substrates*
}

\author{
MANAPURATHU VERGHESE GEORGE \\ Photosciences and Photonics Division, Regional Research Laboratory, \\ Thiruvananthapuram 695 019, India \\ e-mail: mvgeorge@ rediffmail.com
}

MS received 24 July 2003

Abstract. A brief overview of our scientific contributions over the past few years and the results of some of our recent studies on fullerene clusters are presented.

Keywords. Electron transfer processes; functional group transformations; phototransformations; transient intermediates; fullerene clusters; photophysical studies.

\section{Introduction}

I wish to take this opportunity to thank the Council of CRSI for inviting me to give this lecture. I deeply appreciate this honour. A lifetime achievement lecture, of necessity has to, at least briefly, touch upon one's overall contributions. With this in view, I shall highlight some aspects of our contributions and later present a brief report on a piece of work that we have recently completed, with Dr. George Thomas of our Research Unit, on fullerene clusters.

\section{Past research contributions}

When I look back on our research involvement during the past three decades or so, I find that the overriding theme has been the study of organic transformations, emanating from both vibrationally and electronically excited states and their mechanistic implications. This bias has been primarily due to two factors. One such factor was that the general emphasis in most of the major organic chemistry schools of research in India, when I started my professional career, was in the broad area of natural product chemistry. There was therefore a genuine need at that time for people to look into other important areas of organic chemistry also.

A second factor that influenced our interest in organic transformations was my own professional training and background. I did my Ph D work at St. John's College, Agra, under the guidance of Professor P I Ittyerah on some aspects of Perkin and Knoevenagel condensation reactions. This was followed by a few years of post-doctoral training, in

*Based on the CRSI Lifetime Achievement (Gold Medal 2001) lecture given at the Annual Meeting of the Chemical Research Society of India on 2 February 2002 in the National Chemical Laboratory, Pune 
association with some of the well-known names in organic chemistry at that time. This includes two years with the late Professor George F Wright at the University of Toronto, where we studied the conformation of piperazine derivatives through dipole moment measurements, and also the structure elucidation of the Traube compound. This was followed by one year with the late Professor Henry Gilman at Iowa State University, where our interest centred around organolithium reagents and organosilicon chemistry. Subsequently, two years were spent with the late Professor Melvin S Newman at the Ohio State University, where we concentrated on the synthesis of sterically hindered aromatic hydrocarbons and tried to evaluate their strain energies through thermochemical measurements. I then spent one year with the late Professor Sir Derek Barton at the Imperial College of Science and Technology, London, where we evolved a facile procedure for the decarboxylation of aliphatic secondary and tertiary carboxylic acids through the photodecarbonylation of the corresponding acyl xanthates. Lastly, I spent one year with Professor Rolf Huisgen at the University of München, where we studied the kinetics of 1,3-dipolar cycloaddition reactions of certain azomethine imines with different dipolarophiles to evaluate the rates of addition and also other relevant thermodynamic parameters to judge whether or not those reactions proceeded through a concerted pathway.

I had spent a fairly long time on post-doctoral assignments. However, I would like to mention here that I was not looking for a job abroad during this time, even though they were readily available. I had made a promise to myself before leaving India on 11 February 1956 that I would return to India after my training and look for a job here, only failing which I was free to look for a position elsewhere abroad. In fact, when I returned to India in February 1963, I had no definite offer for a placement. I first joined the Organic Chemistry Department of the Indian Institute of Science, Bangalore as a CSIR Pool Officer. Fortunately I had to remain in that position only for a couple of weeks or so, since a position at the Indian Institute of Technology (IIT), Kanpur soon became available.

My professional career in India formally started in April 1963, when I joined the Department of Chemistry at the IIT, Kanpur. I had the great privilege of being associated with some distinguished colleagues, Professor C N R Rao, Professor P T Narasimhan and many others. It was a wonderful opportunity to further our professional interests and simultaneously build up a good Department of Chemistry. I would like to mention here that this was possible to a large extent due to the generous support and encouragement that we received from the late Dr Kelkar, the then Director and the late Dr Muthanna, the then Deputy Director of IIT, Kanpur and we remain grateful to them.

I stayed on in Kanpur till the end of October 1988, the mandatory date of retirement in my case. In November 1988, I moved over to the Regional Research Laboratory (RRL), Thiruvananthapuram where I am still associated with the Photosciences and Photonics Division. I would like to dedicate this presentation to all those who were associated with me as $\mathrm{Ph}$ D students and post-doctoral fellows at IIT, Kanpur and also to my colleagues at the Photosciences and Photonics Division of RRL, Thiruvananthapuram.

As I mentioned earlier, our research contributions could be broadly classified under the general heading of study of organic transformations under thermal and photochemical conditions and their mechanistic implications. Some of the major areas in which we have been interested include electron transfer processes, organic reactions and functional group transformations, organic phototransformations and study of transient intermediates, through nanosecond and picosecond laser flash photolysis techniques. 


\section{$2.1 \quad$ Electron transfer processes}

Study of electron transfer processes has been an area in which we have been interested for a long time. Initially, we were interested in the generation of radical anions and dianions by electron transfer processes, through the reaction of alkali metals with unsaturated organic substrates in polar, aprotic solvents. ${ }^{1}$ These reactive intermediates were successfully employed for the synthesis of a variety of interesting heterocycles containing elements such as silicon and germanium. Some of our contributions in this area are summarized in one of our reviews on organosilacyclenes in Organometallic Chemistry Reviews (1976). ${ }^{2}$

Another aspect of this investigation dealt with spectroscopic studies of radical ions. Jointly with Professor Rao, we examined the electronic spectra of a large number of radical ions and related species, generated from aromatic hydrocarbons, heterocycles, ketyls and related systems, azo compounds and nitro and nitroso compounds. These studies are summarized in a review in Applied Spectroscopy Reviews. ${ }^{3}$ Even today we have continued interest in electron transfer reactions but the emphasis has changed to mostly photoinduced electron transfer processes. Some of the scientists in our Unit at present are studying photoinduced electron transfer processes in donor-acceptor systems to explore ways by which better charge separation and stabilization can be achieved in these systems.

\subsection{Organic reactions and functional group transformations}

We shall now move on to another area of interest, namely organic reactions and functional group transformations. Our studies on oxidations of organic compounds employing non-stoichiometric oxides such as manganese dioxide and nickel peroxide, photooxygenation of heterocycles, nucleophilic additions to acetylenic esters and ketones can all be grouped under this general heading. We have carried out detailed studies involving the oxidation of a variety of organic substrates, employing manganese dioxide ${ }^{4}$ and nickel peroxide ${ }^{5}$ and have found that these reagents could be used for selective transformation of functional groups. Most of these reactions proceed through free-radical intermediates, which invariably lead to interesting coupling products also. We have also carried out detailed studies on photooxygenations, particularly of heterocyclic compounds, which resulted in several interesting oxygenated products. ${ }^{6}$

Our interest in the chemistry of acetylenic esters was primarily due to the potential it offered for the synthesis of newer heterocycles and also for newer ways of building known heterocycles. In this context we have examined, in detail, the stereochemistry of addition of different nucleophiles to acetylenic esters such as dimethyl acetylenedicarboxylate and have successfully used the initially formed adducts in many cases for the building of interesting heterocycles. ${ }^{7}$

\subsection{Organic phototransformations}

One of the major areas of our interest has been the study of photoinduced transformations of organic substrates. When we started work in this area, only a very few people in India were interested in organic photochemistry, although there were some people engaged in photophysical studies. Today we have several active groups in India working on different aspects of photochemistry. Also, the scope of photochemistry has widened considerably and borders on other areas such as material science and photobiology. 
Our initial interest in photochemistry, as I had stated earlier, was to evolve a simple photochemical procedure for the decarboxylation of secondary and tertiary carboxylic acids through the photodecarbonylation of the corresponding acyl xanthates. Subsequently, we have carried out detailed investigations on the photochemistry of both acyl and aroyl xanthates, including the characterization of the transient intermediates involved in these reactions. ${ }^{9}$ I am not listing the details of these studies here for the want of space.

During the course of our studies we have examined the phototransformations of several classes of organic compounds with a view to studying the nature of the products formed in these reactions and also to understand the intricate mechanistic details. In all these studies, we were particularly interested in the generality of such processes. Of the many types of compounds we have examined, I would like to mention one specific example, to illustrate how one specific problem leads to another and ultimately leads to a whole area of investigation. The specific study I wish to highlight is the photolysis of sydnones (scheme 1). ${ }^{10}$

Sydnones are a class of compounds named after Sydney in Australia, where initial studies on their preparation and characterization were carried out. Sydnones are referred to as mesoionic compounds and there have been some stray reports, prior to our work, that some of the sydnone derivatives changed colour on exposure to light. We were interested in investigating this problem and hence have systematically explored the photochemistry of some sydnone derivatives.

$\mathrm{N}, \mathrm{C}$-diphenylsydnone, for example, on photolysis in benzene gives 2,4,5-triphenyl1,2,3-triazole as the major product $(\sim 30 \%) .{ }^{10}$ We have shown, through detailed studies, that 1,2-bisphenylazostilbene is the actual precursor for the triazole formation in this reaction. In a separate experiment we had observed that the bisphenylazostilbene is quantitatively converted to the triazole derivative, on treatment with carbon disulphide. Careful isolation of the product mixture showed that both phenylisothiocyanate and elemental sulphur were the other products formed in this reaction. This prompted us to speculate that the reaction is proceeding through an intermediate cycloadduct, which then decomposes to give the observed products. ${ }^{11}$

If the suggested intermediate is actually involved, then we reasoned that bisphenylazostilbene must be undergoing a pentadienyl type of cyclization, resulting in a
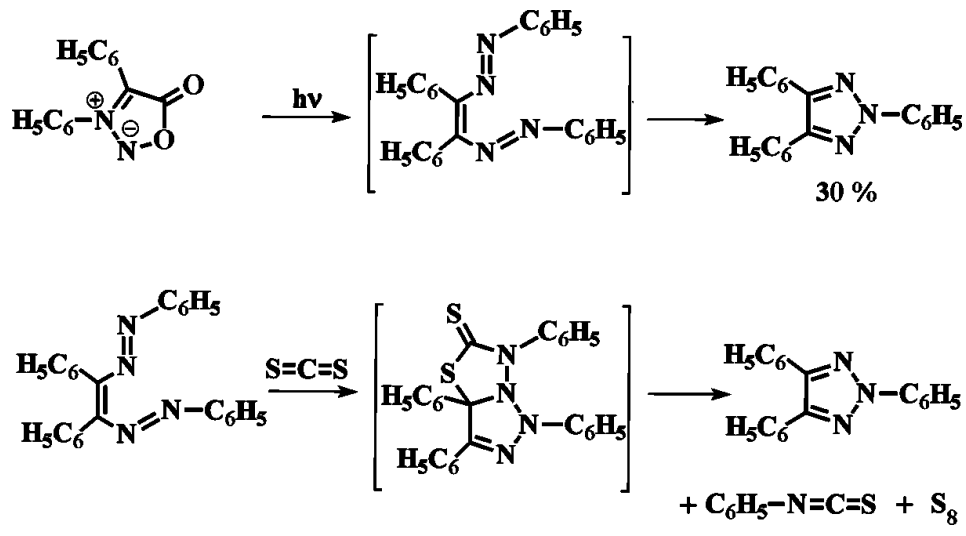

Scheme 1. 
1,3-dipolar intermediate, which in turn can add to different dipolarophiles. We have shown that this is indeed true by treating various dipolarophiles with the starting bisphenylazostilbene and isolating the corresponding cycloadducts. ${ }^{11,12}$ One specific example, namely the reaction of dimethyl acetylenedicarboxylate with bisphenylazostilbene is shown in scheme 2. Mention may be made that recent X-ray structure determination has revealed that the actual structure of the final product is one which arises through a rearrangement of the initially formed adduct. ${ }^{13}$

It is logical to assume that the hetero-1,3,5-hexatriene cyclizations that we have outlined here should be applicable to a wide variety of triene systems. Some of these systems which we have examined and also identified from scattered literature reports are listed in chart 1 . The generality of such hetero hexa-1,3,5-triene cyclizations have been summarized in a review article in Angewandte Chemie (1980). ${ }^{14}$

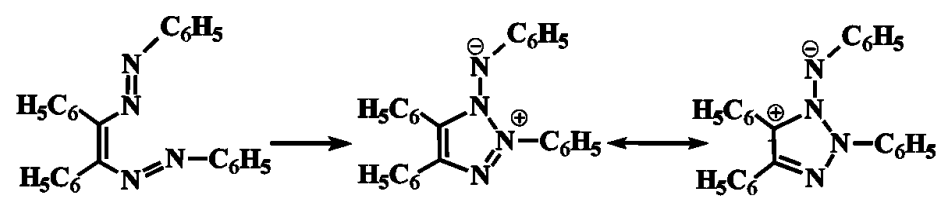

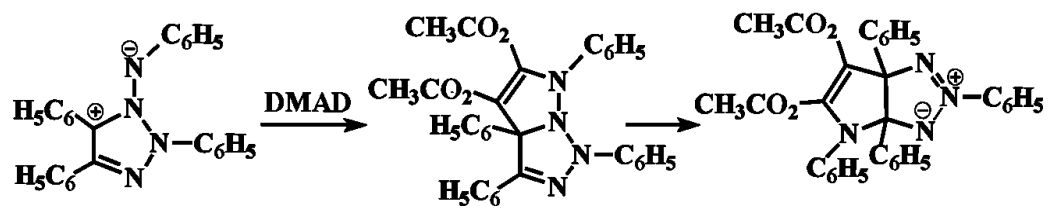

Scheme 2.<smiles>CN=C(C)C(C)=C(C)C=C(C)C</smiles><smiles></smiles><smiles>Cc1sc(=S)c(C)c(C)c1C</smiles><smiles>CC(=O)C(C)=C(C)C</smiles><smiles>CC(C)=C(C)/C(C)=C(/C)N=O</smiles><smiles>CC(C)=N/C(C)=C(/C)N=O</smiles><smiles>CC(C)=C/C(C)=N\N=C(C)C</smiles><smiles>CC(=O)C(C)=C(C)C(C)=S</smiles><smiles>CN=N/C(C)=C(/C)N=C(C)C</smiles><smiles>CN=N/C(C)=C(/C)N=NC</smiles><smiles>CN=N/C(C)=C(/C)N=O</smiles><smiles>C/C(N=O)=C(/C)N=O</smiles>

Chart 1. 

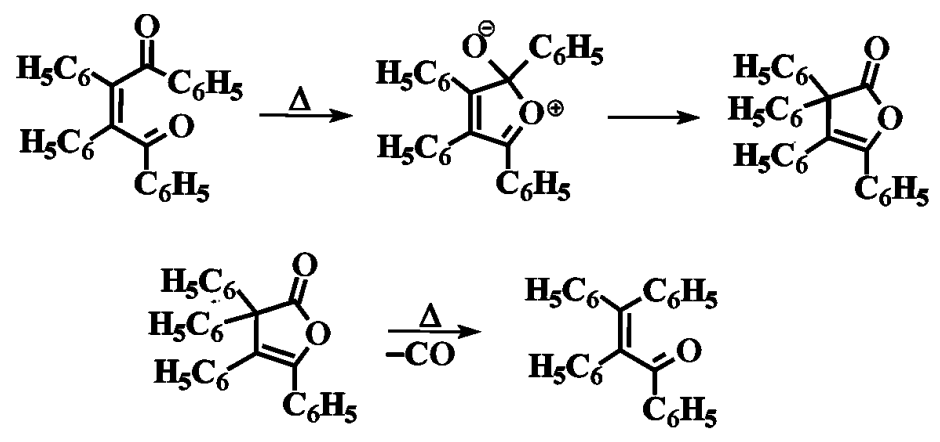

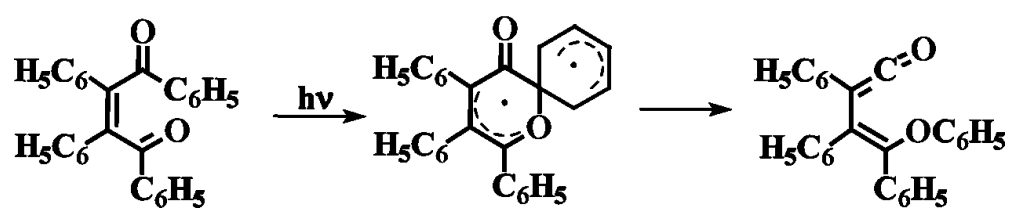

Scheme 3.
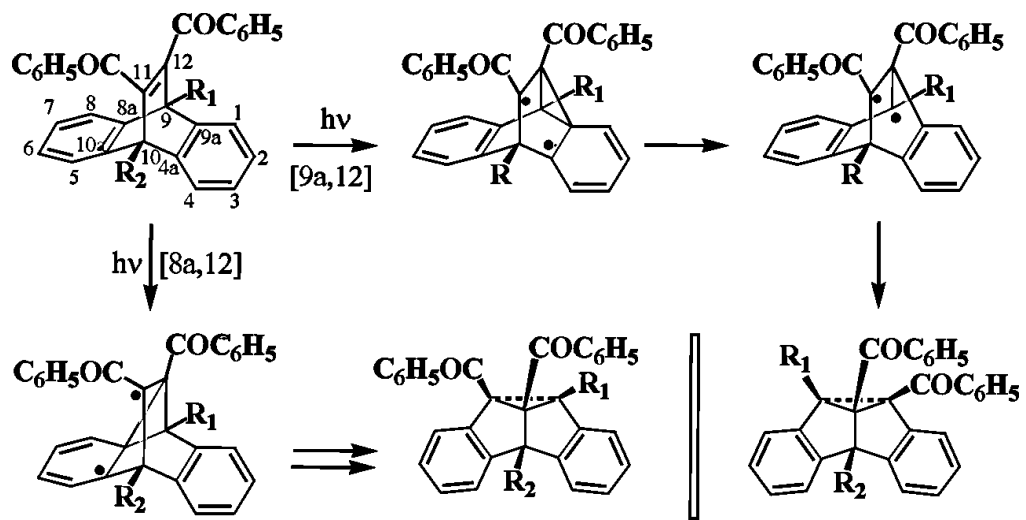

Scheme 4.

I would now like to draw your attention to one of these systems, namely 1,2dibenzoylstilbene, and to look more closely at the thermal and photochemical transformations of this system. The thermal transformation of 1,2-dibenzoylstilbene has been reported earlier by Zinin to give a furanone intermediate, arising through a rearrangement. ${ }^{15}$ This furanone undergoes decarbonylation on further heating to give an olefinic product. ${ }^{16,17}$ These transformations are shown in scheme 3 . The photochemistry of this compound, follows an entirely different route as first observed by Griffin, ${ }^{18}$ and Zimmerman. ${ }^{19}$ The end-product in this case is a ketene intermediate, which can lead to a carboxylic acid or ester, depending on whether the reaction is carried out in aqueous or alcoholic medium. ${ }^{20}$ 
We have explored the photochemistry of several 1,2-dicarbonyl systems, including multichromophoric substrates. I shall skip most of these studies and directly come to our detailed investigations on the photochemistry of dibenzobarrelenes. We have spent considerable time in exploring the rich photochemistry of these systems. Dibenzobarrelenes containing 1,2-dibenzoylalkenes are examples of multichromophoric systems, containing both the 1,2-dibenzoyl chromophore and the barrelene chromophore.

The photochemistry of dibenzobarrelenes is extremely interesting since it can proceed through multichannel pathways. Some examples of these pathways are indicated in scheme 4. We had examined the photochemistry of dibenzobarrelenes in great detail to ascertain the role of steric and electronic effects of the substituent groups at the bridgehead positions. It has been observed that both electronic and steric effects of the bridgehead substituent play a major role in the regioselectivity of these rearrangements. Further, it has been observed that the primary photoproducts, namely dibenzosemibullvalenes undergo secondary transformations, depending on the substituents present in them and also on the reaction conditions. Thus, for example, irradiation of a symmetrically disubstituted dibenzobarrelene such as the 9,10-dimethyl-substituted dibenzobarrelene gave a mixture of dibenzocyclooctatetraene and a dibenzopentalene derivative, in addition to an oxygenated hexacyclic peroxy carbinol as shown in scheme 5..$^{21,22}$ We have carried out detailed studies, employing several bridgehead mono and disubstituted dibenzobarrelene derivatives. The results of these studies are summarized in several publications from our group. ${ }^{21-32}$ Our studies point out that the photochemistry of suitably substituted dibenzobarrelenes provides a facile route to the synthesis of several interesting polycyclic ring systems.

2.4 Study of transient intermediates through nanosecond and picosecond laser flash photolysis techniques

Our study of transient intermediates became important in order to understand the mechanistic details of the phototransformations that we had examined. In this context, we have investigated a wide variety of organic substrates, known to undergo photo-
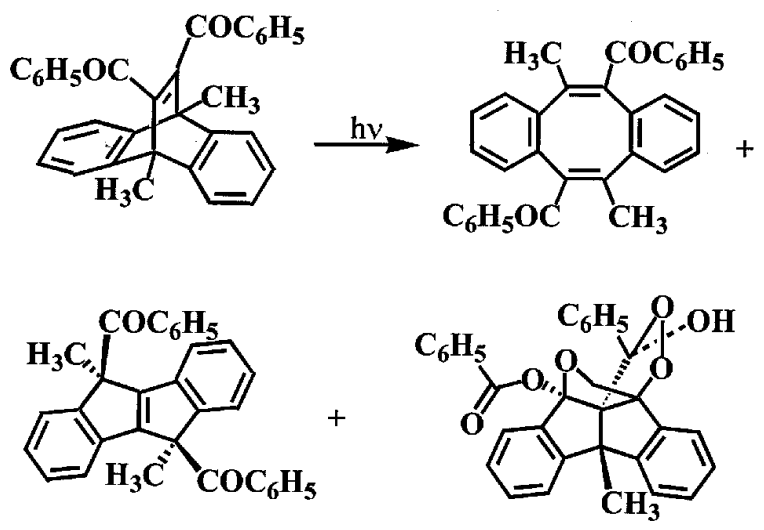

Scheme 5 . 
transformations. Some of the classes of compounds that we have studied include furanones, ${ }^{33-37}$ furanoxy radicals, ${ }^{38,39}$ epoxy compounds, ${ }^{40,41}$ benzoylaziridines, ${ }^{42,43}$ pyrones and chromones, ${ }^{44}$ benzopyranols, ${ }^{45}$ nitrile imines, ${ }^{46}$ aromatic nitrones, ${ }^{47}$ and dinitrodiphenylmethanes, ${ }^{48}$ besides dibenzobarrelenes. Our primary objective in these studies has been to understand the mechanistic details of the different phototransformations.

\section{Recent studies on fullerene clusters}

So far I have tried to give a brief overview of some of our concerns during the past several years. I would now like to present a brief report on a recent piece of work that we have completed, jointly with Dr. George Thomas of our Unit, on fullerene clusters. The design of molecular systems, which can spontaneously self-assemble to form larger aggregates or clusters, is of current interest in the domain of supramolecular chemistry. Fullerenes and their derivatives are known to form clusters in mixed solvents that are optically transparent and thermodynamically stable. Recent studies have shown that fullerene-based cluster systems possess interesting photophysical and photochemical properties. In the present investigation we have examined the photophysical and photochemical behaviour of the monomer and cluster forms of bis- and tris-fullerene derivatives to understand the factors that influence charge stabilization in these clusters.

\subsection{Bis- $\left(C_{60}\right)$ and tris- $\left(C_{60}\right)$ fullerenes}

The fullerene derivatives that we have examined are shown in chart 2 . We had reported earlier ${ }^{49}$ the results of our studies, employing the monofunctionalized $\mathrm{C}_{60}$ derivative

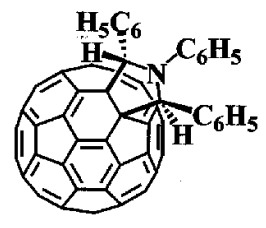

Mono- $\left(\mathbf{C}_{60}\right)$

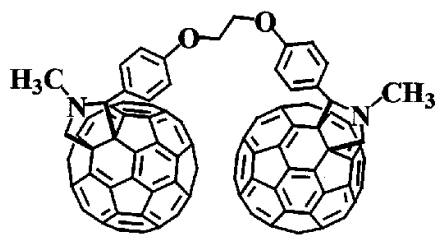

Bis- $\left(\mathbf{C}_{60}\right)$

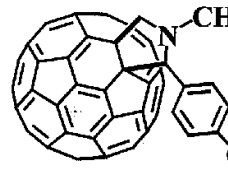<smiles>CCOCCOc1cc(OCCOC)cc(OCCOC)c1</smiles>

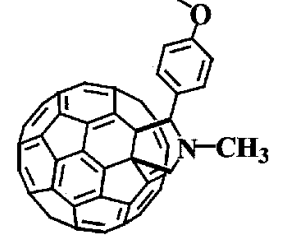

Tris- $\left(\mathrm{C}_{60}\right)$

Chart 2. 
(mono- $\left(\mathrm{C}_{60}\right)$ ). As reported earlier, the mono- $\left(\mathrm{C}_{60}\right)$ was prepared through the reaction of an azomethine ylide, generated from 1,2,3-triphenylaziridine with $\mathrm{C}_{60}$. The syntheses of both bis- $\left(\mathrm{C}_{60}\right)$ and tris- $\left(\mathrm{C}_{60}\right)$ have been achieved through the reaction of the corresponding azomethine ylides, formed from the precursor dialdehyde and trialdehyde respectively, and $\mathrm{N}$-methylglycine, with $\mathrm{C}_{60} .50$

\subsection{Absorption spectra of bis- $\left(C_{60}\right)$ and tris- $\left(C_{60}\right)$ clusters}

The absorption spectra of bis- $\left(\mathrm{C}_{60}\right)$ and tris- $\left(\mathrm{C}_{60}\right)$ fullerenes are characteristic of the mono- $\left(\mathrm{C}_{60}\right)$ derivative. In mixed polar/non-polar solvents (e.g. acetonitrile and toluene), however, these fullerenes readily form transparent clusters. These clusters exhibit broad featureless spectra, with increased molar extinction coefficients. These clusters are quite stable at room temperature and can be reverted back to the corresponding monomeric forms, on increasing the fraction of the nonpolar solvent (toluene).

\subsection{Emission spectra of bis- $\left(C_{60}\right)$ and tris- $\left(C_{60}\right)$ monomers and clusters}

Both bis- $\left(\mathrm{C}_{60}\right)$ and tris- $\left(\mathrm{C}_{60}\right)$ possess characteristic emission bands with a maximum centred around $715 \mathrm{~nm}$, which is similar to that of the monofunctionalized fullerene derivative. The similarity of the absorption and emission features of both these with those of the mono- $\left(\mathrm{C}_{60}\right)$ indicates that the individual fullerene moieties maintain their identity in displaying the excited state properties. Both bis- $\left(\mathrm{C}_{60}\right)$ and tris- $\left(\mathrm{C}_{60}\right)$ exhibit an additional shoulder around $775 \mathrm{~nm}$ in the emission spectra. This band is particularly more prominent in bis- $\left(\mathrm{C}_{60}\right)$. The new shoulders observed in bis- $\left(\mathrm{C}_{60}\right)$ and tris- $\left(\mathrm{C}_{60}\right)$ derivatives are likely to arise from intramolecular interaction between the two excited fullerene moieties. Preliminary studies indicate that relative intensities of both these bands are unaffected in the temperature range of $5-40^{\circ} \mathrm{C}$ and solvent polarity (toluene to benzonitrile). The excitation spectra of bis $\left(\mathrm{C}_{60}\right)$ recorded by monitoring the emissions at 710,740 and $775 \mathrm{~nm}$ show similar spectral features that correspond to the absorption spectrum of the monomeric form of bis- $\left(\mathrm{C}_{60}\right)$.

A bathochromic shift $(15-35 \mathrm{~nm})$ in the emission maximum was observed for the clusters of bis- $\left(\mathrm{C}_{60}\right)$ and tris- $\left(\mathrm{C}_{60}\right)$ fullerene derivatives in toluene/acetonitrile mixed solvent system. The emission maximum in both bis- $\left(\mathrm{C}_{60}\right)$ and tris- $\left(\mathrm{C}_{60}\right)$ is observed around $750 \mathrm{~nm}$. The prominent red-shifted band $(750 \mathrm{~nm})$ of these clusters confirms that they continue to exhibit photophysical properties similar to their monomer analogs.

\subsection{Cluster size analysis}

The clusters of bis- $\left(\mathrm{C}_{60}\right)$ and tris- $\left(\mathrm{C}_{60}\right)$ derivatives were characterized using dynamic light scattering method. The maximum cluster diameter for bis- $\left(\mathrm{C}_{60}\right)$ and tris- $\left(\mathrm{C}_{60}\right)$ derivatives were found to be $1.5 \mu \mathrm{m}$ and $150 \mathrm{~nm}$ respectively. Both these clusters showed a wide range of cluster-size distributions. The size distribution of tris- $\left(\mathrm{C}_{60}\right)$ clusters in acetonitrile/toluene is much narrower than that of bis- $\left(\mathrm{C}_{60}\right)$. The TEM images of the clusters of bis- $\left(\mathrm{C}_{60}\right)$ and tris- $\left(\mathrm{C}_{60}\right)$, prepared from acetonitrile/toluene mixed solvent system show different features. It was observed that the self-assembled clusters of tris$\left(\mathrm{C}_{60}\right)$, are spherical in shape with diameter ranging from 100 to $400 \mathrm{~nm}$. A different type of clustering has been observed in the case of bis- $\left(\mathrm{C}_{60}\right)$ clusters, prepared in acetonitrile/ toluene solvent mixture. The clusters show elongated wire or rod-type structures of 
varying lengths $(200 \mathrm{~nm}$ to $1 \mu \mathrm{m})$. These unusual elongated shapes explain the high dispersity observed for bis- $\left(\mathrm{C}_{60}\right)$ cluster suspension in the dynamic light scattering experiments. It is evident that the linear stacking of molecules is preferred over 3dimensional clustering during the aggregation process in the case of bis- $\left(\mathrm{C}_{60}\right)$ clusters. Aggregation of tris- $\left(\mathrm{C}_{60}\right)$, on the other hand, has the geometric potential to form clusters in a three-dimensional fashion. It is evident from TEM pictures that the tris- $\mathrm{C}_{60}$ derivative aggregates uniformly in all directions via hydrophobic interactions to give spherical structures. In both cases, the linker groups containing polar nitrogen as well as oxygen atoms may preferably be exposed to the polar solvent environment. Pictorial representations of the linear and three-dimensional modes of clustering in the case of bis$\left(\mathrm{C}_{60}\right)$ and tris- $\left(\mathrm{C}_{60}\right)$ respectively, are shown in figures 1 and 2 respectively. Molecular modelling calculations of bis- $\left(\mathrm{C}_{60}\right)$ and tris- $\left(\mathrm{C}_{60}\right)$ derivatives were carried out using Titan software. The equilibrium geometries were estimated using semiempirical AMI calculation. The energy minimized conformations of bis- $\left(\mathrm{C}_{60}\right)$ and tris- $\left(\mathrm{C}_{60}\right)$ are shown in figure 3. The distance of separation between the two $\mathrm{C}_{60}$ moieties is found to be $5 \cdot 4 \AA$ for bis $\left(\mathrm{C}_{60}\right)$. Such an energy-minimized structure favours a linear stacking as the adjacent fullerene moieties interact to produce elongated clusters. On the other hand, the three fullerene moieties in tris- $\left(\mathrm{C}_{60}\right)$, are well-separated from each other at distances of 15.9 , 17.7 and $21.86 \AA$. The spatial arrangement of these fullerene moieties favours threedimensional packing, as the intermolecular interaction between fullerene moieties becomes favourable in all directions. Thus, we expect spherical-shaped clustering behaviour for tris- $\left(\mathrm{C}_{60}\right)$.

\subsection{Singlet- and triplet-excited states of bis- $\left(C_{60}\right)$ and tris- $\left(C_{60}\right)$}

Singlet- and triplet-excited states of bis- $\left(\mathrm{C}_{60}\right)$ and tris- $\left(\mathrm{C}_{60}\right)$ derivatives were probed using transient absorption spectroscopy. Upon $355 \mathrm{~nm}$ laser pulse excitation of the bis- $\left(\mathrm{C}_{60}\right)$ in toluene, the picosecond transient absorption spectrum showed the formation of the singlet excited state with characteristic absorption in the $800-900 \mathrm{~nm}$ region. As the singlet excited state decayed, the growth of absorption in the $700 \mathrm{~nm}$ region due to the triplet was observed. Both bis $\left(\mathrm{C}_{60}\right)$ and tris- $\left(\mathrm{C}_{60}\right)$ fullerene derivatives exhibited a lifetime of $1.25 \pm 0.5 \mathrm{~ns}$ for the singlet excited state. The triplet of bis- $\left(\mathrm{C}_{60}\right)$ and tris- $\left(\mathrm{C}_{60}\right)$ absorb around $700 \mathrm{~nm}$ and have lifetimes in the range of 10-20 $\mu \mathrm{s}$. Clusters of both bis- $\left(\mathrm{C}_{60}\right)$ and tris- $\left(\mathrm{C}_{60}\right)$ derivatives exhibit triplet-triplet absorption properties similar to those of the

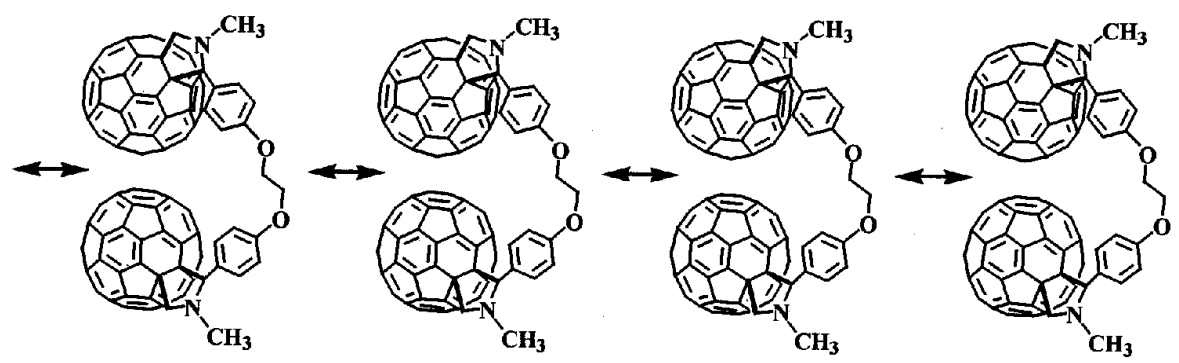

Figure 1. Preferred mode of clustering of bis-fullerenes leading to linear growth. 


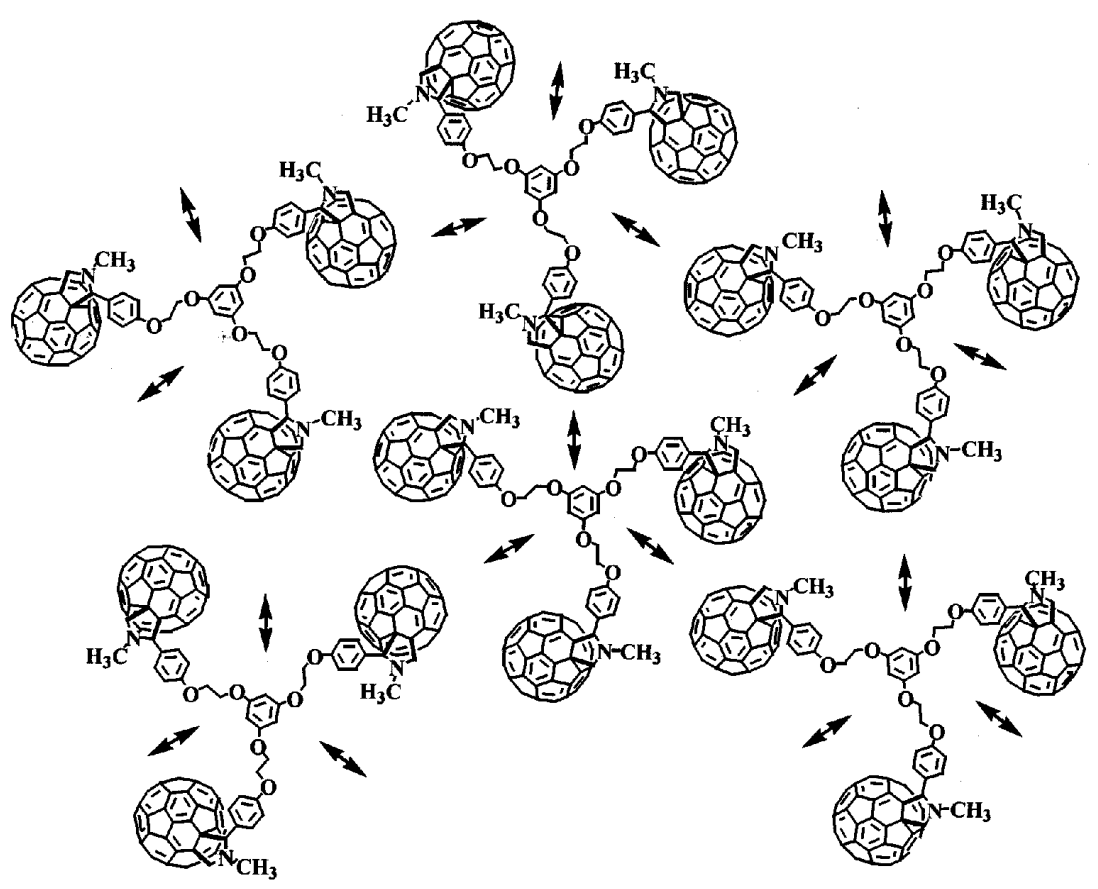

Figure 2. Clustering of tris-fullerenes leading to spherical growth.

monomer form. For example, the triplet-triplet absorption spectra of bis- $\left(\mathrm{C}_{60}\right)$ clusters show absorption maxima around $700 \mathrm{~nm}$ and have lifetimes of about $11 \mu \mathrm{s}$ in acetonitrile/toluene.

\subsection{Excited-state interactions with electron donors}

There have been several studies in recent years, on inter- and intramolecular electrontransfer processes involving fullerenes and electron donors. It was of interest, in the present studies, to examine whether the presence of multiple $\mathrm{C}_{60}$ units on the same carbon backbone can bring about charge stabilization effects, following the electron transfer process. By employing N-methylphenothiazine (NMP) as an electron donor, we probed the excited-state interactions as well as charge stabilization properties of the bis- $\left(\mathrm{C}_{60}\right)$ and tris- $\left(\mathrm{C}_{60}\right)$ derivatives. The experimental procedure involved the addition of a known amount of NMP to acetonitrile solution, prior to the injection of the fullerene solution in toluene. This ensured the trapping of NMP within the network of the fullerene clusters. It was observed that the fluorescence of bis- $\left(\mathrm{C}_{60}\right)$ and tris- $\left(\mathrm{C}_{60}\right)$ derivatives in the monomer and cluster forms is quenched by NMP, as the intermolecular electron transfer process competes with the intersystem crossing process. The bimolecular rate constants $(\mathrm{kq})$ estimated for the singlet-excited state quenching of bis- $\left(\mathrm{C}_{60}\right)$ and tris- $\left(\mathrm{C}_{60}\right)$ derivatives were $5.5 \times 10^{9}$ and $5.3 \times 10^{9} \mathrm{M}^{-1} \mathrm{~s}^{-1}$, respectively. 

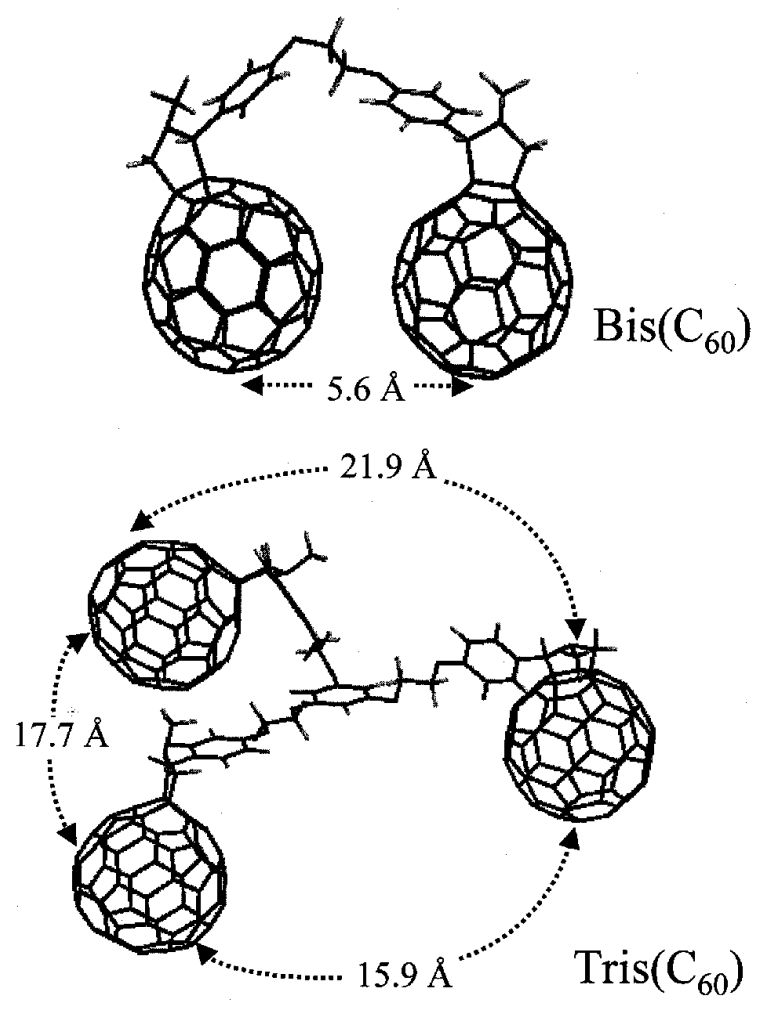

Figure 3. Energy-minimized conformation of bis- $\left(\mathrm{C}_{60}\right)$ and tris- $\left(\mathrm{C}_{60}\right)$ fullerenes.

3.7 Light-induced electron transfer between clusters of bis- $\left(C_{60}\right)$ and tris- $\left(C_{60}\right)$ and electron donors

Using nanosecond laser flash photolysis, photoinduced electron transfer between bis$\left(\mathrm{C}_{60}\right)$ and tris- $\left(\mathrm{C}_{60}\right)$ derivatives and NMP was studied. The transient absorption spectra recorded for the monomer and cluster forms of bis- $\left(\mathrm{C}_{60}\right)$ and tris $-\left(\mathrm{C}_{60}\right)$ in presence of NMP showed similar features with absorption maxima at $520 \mathrm{~nm}$ due to $\mathrm{NMP}^{+\cdot}$ and $1000 \mathrm{~nm}$, due to fullerene anion. The strong absorption of the fullerene anion at $1000 \mathrm{~nm}$ enabled us to evaluate the fate of electron transfer products by analysing the absorption decay in monomer and cluster systems.

\subsection{Charge separation and charge stabilization}

The decay of the fullerene monomer anion depends on the number of fullerene units in the monomer and cluster forms. The decay of the monomer form of the fullerene anions could be fitted to single-exponential decay, whereas biexponential kinetics was necessary to fit the cluster anions. Properties of the triplet excited states and fullerene anions of the fullerene derivatives under investigation are presented in table 1. The fact that first-order decay kinetics is operative for the disappearance of the monomeric form of the fullerene 
Table 1. Properties of triplet excited state and fullerene anion.

\begin{tabular}{|c|c|c|c|c|c|c|c|}
\hline \multirow{2}{*}{$\begin{array}{l}\text { Fullerene } \\
\text { derivative }\end{array}$} & & \multirow{2}{*}{$\begin{array}{c}\text { Abs. } \\
\text { max } \\
\text { triplet } \\
(\mathrm{nm})\end{array}$} & \multirow{2}{*}{$\begin{array}{l}\text { Triplet } \\
\text { lifetime } \\
(\mu \mathrm{s})\end{array}$} & \multirow{2}{*}{$\begin{array}{l}\text { Abs. } \\
\text { max. } \\
\text { anion } \\
(\mathrm{nm})\end{array}$} & \multicolumn{2}{|c|}{ Anion lifetime $^{c}(\mu \mathrm{s})$} & \multirow{2}{*}{$\begin{array}{l}\text { Charge } \\
\text { transfer } \\
\text { quantum }_{\text {yield }^{\mathrm{d}}}\end{array}$} \\
\hline & & & & & $\tau_{1}$ & $\tau_{2}$ & \\
\hline \multirow[t]{2}{*}{ Mono- $\mathrm{C}_{60}$} & Monomer $^{\mathrm{a}}$ & 700 & $16 \cdot 6$ & 1010 & 18 & - & $0 \cdot 11$ \\
\hline & Cluster $^{\mathrm{b}}$ & 700 & $13 \cdot 1$ & 1010 & $16 \cdot 6(64 \%)$ & $109(36 \%)$ & $0 \cdot 13$ \\
\hline \multirow[t]{2}{*}{ Bis- $\mathrm{C}_{60}$} & Monomer $^{\mathrm{a}}$ & 700 & $11 \cdot 9$ & 1000 & 20 & - & 0.09 \\
\hline & Cluster $^{\mathrm{b}}$ & 700 & $5 \cdot 3$ & 1000 & $11 \cdot 8(70 \%)$ & $134(25 \%)$ & 0.07 \\
\hline \multirow[t]{2}{*}{ Tris- $\mathrm{C}_{60}$} & Monomer $^{\mathrm{a}}$ & 700 & $19 \cdot 8$ & 1000 & $34 \cdot 0$ & - & $0 \cdot 11$ \\
\hline & Cluster $^{\mathrm{b}}$ & 700 & $3 \cdot 1$ & 1000 & $12 \cdot 0(85 \%)$ & $146(15 \%)$ & $0 \cdot 06$ \\
\hline
\end{tabular}

${ }^{\mathrm{a}}$ In toluene; ${ }^{\mathrm{b}}$ in 19:1 acetonitrile:toluene mixed solvent; ${ }^{\mathrm{c}}$ numbers in brackets indicate fractional contribution to the overall decay; ${ }^{\mathrm{d}}$ measured from the fullerene anion yield $(\varepsilon(1000 \mathrm{~nm})=$ $\left.16250 \mathrm{M}^{-1} \mathrm{~cm}^{-1}\right)$ and benzophenone triplet as the actinometry reference $(\varepsilon(530 \mathrm{~nm})=$ $7600 \mathrm{M}^{-1} \mathrm{~cm}^{-1}$ )

anions suggests that the electron transfer products exist within close proximity of each other. Hence, the fast back-electron transfer occurs mainly from close contact pairs and is not influenced by the diffusion of the two species within the bulk medium. On the other hand, in the cluster systems we see the presence of two components. The faster component arises from the close-lying charge-separated pair, whereas the slower component involves the charge that is localized farther away from $\mathrm{NMP}^{+\cdot}$ species. Thus, the clustering of fullerene moieties favours charge stabilization as the charge can quickly migrate from one fullerene moiety to another with ease.

From the data presented in table 1, it is evident that the fullerene anion lifetime increases with increasing numbers of fullerene moieties within the same cluster. Thus, an increase in the lifetime of $18-34 \mu$ s was observed for an increase in the number of fullerene units from one to three. These observations further support our earlier argument that stabilization of charge can be achieved by bringing together several fullerene units in close proximity. Indeed clusters of each of these fullerene derivatives show a long-lived component with a lifetime greater than $100 \mu \mathrm{s}$.

\section{Conclusions}

Both bis- $\left(\mathrm{C}_{60}\right)$ and Tris- $\left(\mathrm{C}_{60}\right)$ fullerene derivatives form optically transparent clusters in solvent mixtures of toluene and acetonitrile. These clusters were characterized by dynamic light scattering experiments and TEM studies. In contrast to mono- $\left(\mathrm{C}_{60}\right)$ derivatives, which forms isolated clusters, both bis- $\left(\mathrm{C}_{60}\right)$ and tris- $\left(\mathrm{C}_{60}\right)$ derivatives form nanorods or wires, or spherically entangled structures respectively. The singlet- and triplet-state properties of these fullerene-based systems were characterized in their monomeric as well as cluster environment. Based on intermolecular electron transfer studies between the clusters of bis- $\left(\mathrm{C}_{60}\right)$ as well as tris- $\left(\mathrm{C}_{60}\right)$ with $\mathrm{N}$-methylphenothiazene, it is concluded that the cluster network of nanorods or spherical entangled structure possesses better charge stabilization properties compared to the corresponding monomeric forms. 


\section{Acknowledgements}

This is contribution No. PPD (PRU)-174 from RRL, Thiruvananthapuram. The author thanks all his coworkers, whose names appear in the references cited in this article and others for their contributions. Special thanks are due to Dr K George Thomas, Dr V Biju and Mr P K Sudeep of the Photosciences and Photonics Division, and Dr. Prashant Kamat and Mr Said Barazzouk of the Radiation Laboratory of the University of Notre Dame, USA for their contribution to the fullerene studies. Financial support from the Council of Scientific and Industrial Research and the Department of Science and Technology, Government of India, the Jawaharlal Nehru Centre for Advanced Scientific Research, Bangalore and the Radiation Laboratory of the University of Notre Dame, USA, is acknowledged. The author would like to place on record his special appreciation for Professor Robert $\mathrm{H}$ Schuler, former Director, and members of the Radiation Laboratory of the University of Notre Dame, USA for the generous help and support extended to him for his work during the past several years.

\section{References}

1. Kalyanaraman V and George M V 1973 J. Org. Chem. 38 507; Kalyanaraman V and George M V 1973 J. Organometal. Chem. 47225

2. George M V and Balasubramanian R 1976 Organometal. Chem. Rev. 103 (ed.) D Seyferth (New York: Elsevier Scientific)

3. Rao C N R, Kalyanaraman V and George M V 1969 Appl. Spectrosc. Rev. 3153 (New York: Marcel Dekker)

4. Bhatnagar I and George M V 1967 J. Org. Chem. 32 2252; Bhatnagar I and George M V 1968 Tetrahedron 24 1293; Bhatnagar I and George M V 1968 J. Org. Chem. 332417

5. Balachandran K S and George M V 1975 Chem. Rev. 75 491; George M V 1980 Organic synthesis by oxidation with metal oxides 373 (eds) W J Mijs and C H I de Jonge (New York: Plenum)

6. George M V and Bhat V 1979 Chem. Rev. 79447

7. George M V, Khetan S K and Gupta R K 1976 Adv. Heterocycl. Chem. 19279 (eds) A R Katritzky and A J Boulton (New York: Academic Press); Junjappa H, Saxena M K, Ramaiah D, Lohray B B, Rath N P and George M V 1998 J. Org.Chem. 639801

8. Barton D H R, George M V and Tomoeda M 1962 J. Chem. Soc. 622

9. Singh S N and George M V 1971 J. Org. Chem. 36 615; Shah A, Singh S N and George M V 1968 Tetrahedron Lett. 3983; Singh S N and George M V 1972 J. Org. Chem. 37 1375; Singh S N and George M V 1975 Tetrahedron 31 2029; Weir D, Ajayaghosh A, Muneer M and George M V 1990 J. Photochem. Photobiol. A52 425

10. Angadiyavar C S and George M V 1971 J. Org.Chem. 361589

11. Angadiyavar C S, Sukumaran K B and George M V 1971 Tetrahedron Lett. 633

12. Sukumaran K B, Angadiyavar C S and George M V 1972 Tetrahedron 283987

13. Ramaiah D, Rath N P and George M V 1998 Acta Cryst. C54 872

14. George M V, Maitra A and Sukumaran K B 1980 Angew. Chem., Int. Ed. Engl. 19973

15. Zinin N 1872 Chem. Ber. 51104

16. Japp F R and Klingemann F 1890 J. Chem. Soc. 662

17. Chipman D M, Chauhan S M S and George M V 1980 J. Org. Chem. 453187

18. Griffin G W and O'Connell E J 1962 J. Am. Chem. Soc. 844148

19. Zimmerman H E, Durr H G C, Lewis R G and Bram S 1962 J. Am. Chem. Soc. 844149

20. Lahiri S, Dabral V, Chauhan S M S, Chakachery E, Kumar C V, Scaiano J C and George M V 1980 J. Org. Chem. 453782

21. Kumar C V, Murthy B A R C, Lahiri S, Chakachery E, Scaiano J C and George M V 1984 J. Org. Chem. 494923

22. Asokan C V, Kumar S A, Das S, Rath N P and George M V 1991 J. Org. Chem. 565890

23. Murthy B A R C, Prathapan, S, Kumar C V, Das P K and George M V 1985 J. Org. Chem. 50 2533 
24. Prathapan S, Ashok K, Cyr D R, Das P K and George M V 1987 J. Org. Chem. 525512

25. Prathapan S, Ashok K, Gopidas K R, Rath N P, Das P K and George M V 1990 J. Org. Chem. 551304

26. Kumar S A, Asokan C V, Das S, Wilbur J A, Rath N P and George M V 1993 Photochem. Photobiol. A71 27

27. Kumar S A, Rajesh C S, Das S, Rath N P and George M V 1995 J. Photochem. Photobiol. A86 177

28. Mathew T, Kumar S A, Das S, Rath N P and George M V 1996 J. Photochem. Photobiol. A95 5468

29. Ajaya Kumar S, Mathew T, Das S, Rath N P and George M V 1996 Acta Cryst. C52 2797; Muneer M, Rath N P and George M V 1996 Acta Cryst. C52 2800; Mathew T, Rath N P and George M V 1996 Acta Cryst. C52 942

30. Ramaiah D, Kumar S A, Asokan C V, Mathew T, Das S, Rath N P and George M V 1996 J. Org. Chem. 615468

31. Ajayakumar S, Ramaiah D, Eldho N V, Das S, Rath N P and George M V 1997 J. Photochem. Photobiol. A103 69

32. Sajimon M C, Ramaiah D, Muneeer M, Ajithkumar E S, Rath N P and George M V 1999 J. Org. Chem. 646347

33. Lohray B B, Kumar C V, Das P K and George M V 1984 J. Am. Chem. Soc. 1067352

34. Davis H F, Lohray B B, Gopidas K R, Kumar C V, Das P K and George M V 1985 J. Org. Chem. 503685

35. Gopidas K R, Cyr D R, Das P K and George M V 1987 J. Org. Chem. 525505

36. Gopidas K R, Lohray B B, Rajadurai S, Das P K and George M V 1987 J. Org. Chem. 522831

37. Prathapan S, Ashok K, Cyr D R, Das P K and George M V 1988 J. Org. Chem. 535826

38. Bhattacharyya K, Das P K, Fessenden R W, George M V, Gopidas K R and Hug G L 1985 J. Phys. Chem. 894164

39. Bhattacharyya K, Das P K, Fessenden R W, George M V, Gopidas K R, Hiratsuka H, Hug G L, Rajadurai S and Samanta A 1989 J. Am. Chem. Soc. 1113542

40. Murthy B A R C, Kumar C V, Dabral V, Das P K and George M V 1984 J. Org. Chem. 49 4165

41. Kumar C V, Ramaiah D, Das P K and George M V 1985 J. Org. Chem. 502818

42. Bhattacharyya K, Ramaiah D, Das P K and George M V 1986 J. Phys. Chem. 903221

43. Ramaiah D, Cyr D R, Barik R, Gopidas K R, Das P K and George M V 1992 J. Phys. Chem. 961271

44. Bhattacharyya K, Ramaiah D, Das P K and George M V 1986 J. Phys. Chem. 905984

45. Ramaiah D, Scaria P M, Cyr D R, Das P K and George M V 1988 J. Org. Chem. 532016

46. Bhattacharyya K, Ramaiah D, Das P K and George M V 1987 J. Photochem. 3663

47. Cyr D R, Mathew T, Ashok K, Das P K and George M V 1991 J. Photochem. Photobiol. A60 161

48. Mathew T, Ramaiah D, Joshua C P, Weir D and George M V 1993 J. Photochem. Photobiol. A70 245

49. Biju V, Barazzouk S, George Thomas K, George M V and Kamat P V 2001 Langmuir 172930

50. Biju V, Sudeep P K, George Thomas K, George M V, Barazzouk S and Kamat P V 2002 Langmuir 181831 